\section{Darcy's Law}

\section{Renato Macciotta}

School of Engineering Safety and Risk Management, University of Alberta, Edmonton, AB, Canada

\section{Definition}

Darcy's law defines the rate of water flow through porous media, assuming a laminar flow. It states that the rate of flow per unit, cross-sectional area is equal to the product of the hydraulic conductivity of the material and the hydraulic gradient.

\section{Overview}

Henry Darcy (1803-1858), a French waterworks in Dijon, revealed a proportionality between the flow rate in clean sands and the applied hydraulic gradient. In its simplest form:

$$
q=v A=k i A=k \frac{\Delta h}{L} A
$$

where $q$ is the flow rate through the cross-sectional area $(A)$; $v$ is the flow velocity; $i$ is the hydraulic gradient, calculated as the difference in pore pressure head per unit length $(\Delta h / L)$; and $k$ is the hydraulic conductivity.
Use

Darcy's law is widely used in the fields of Engineering Geology, Hydrogeology, Geotechnical Engineering, and Environmental Sciences, in particular for estimating seepage rates, flow patterns, drainage, and contaminant transport through earth materials. Darcy's law can be expanded for fluids other than water, for three-dimensional flows through anisotropic materials, and to consider inertial effects and drag forces (Nield and Bejan 2006).

\section{Cross-References}

D Drainage

- Engineering Geology

$\checkmark$ Geotechnical Engineering

$\checkmark$ Hydrogeology

- Pore Pressure

\section{References}

Nield DA, Bejan A (2006) Convection in porous media, 3rd edn. Springer Science+Business Media Inc, New York 